\title{
RECURRENT MARJOLIN'S ULCER WITH REGIONAL LYMPH NODE METASTASIS
}

\author{
Anjali Sethi, Deepak Sethi, Vishwas Johri
}
1. Assistant Professor, Department of Surgery, RNT Medical College and MB Govt. Hospital, Udaipur, Rajasthan, India.
2. Medical Officer, Department of Surgery, RNT Medical College and MB Govt. Hospital, Udaipur, Rajasthan, India.
3. Assistant Professor, Department of Surgery, RNT Medical College and MB Govt. Hospital, Udaipur, Rajasthan, India.

\section{CORRESPONDING AUTHOR}

Dr. Deepak Sethi,

303 Akshansh Apartments,

Keshav Nagar, UDAIPUR - 313001

E-mail: deepanjali_d1972@yahoo.com,deepanjali.d1972@gmail.com

Ph: $00912942471892,00919414248134$.

ABSTRACT: Marjolin's ulcer is a malignant tumour developing in a chronic skin lesion (burn scar, vaccination scar, non-healing wound etc.). The majority of cases reported are squamous cell carcinoma. Surgery remains the first treatment of choice (resection with $2 \mathrm{cms}$. safety margin of healthy skin for primary squamous cell carcinoma Marjolin ulcers and $2.5 \mathrm{cms}$. safety margin for recurrent cases). Recurrence after surgery and regional lymph node metastasis are not uncommon (17\% \& 30\% respectively).We presents a case report and literature review of Recurrent Marjolin's Ulcer with regional Lymph Node Metastasis. Marjolin's ulcer should be considered as a significant post-burn complication; it should be treated with full emphasis on adequate local clearance and regular follow up for many years; if not treated adequately, it may lead to complicated recurrence.

KEY WORDS: Marjolin's Ulcer, Recurrent, Lymph Node Metastasis.

INTRODUCTION: Marjolin's ulcer is a malignant tumour developing in a chronic skin lesion (burn scar, vaccination scar, non-healing wound etc.).(1) The majority of cases reported are squamous cell carcinoma but other type of malignancy such as basal cell carcinoma, malignant melanoma, liposarcoma, osteosarcoma, and fibrosarcoma can also be seen although rare.(2) The incidence of burn scar undergoing malignant transformation has been reported to be $0.77-2 \%$. 3)

CASE REPORT: A 22 year old male was presented to our surgical department with exophytic ulcerated growth of size $7 \times 7 \mathrm{~cm}$. near angle of right scapula. He had a past history of burn over anterior chest wall, back and left arm 12 years ago that healed completely by conservative management. Approx. 11 years after initial insult, the patient developed an ulcer on the back over burn scar. It gradually increased in size to become exophytic growth of size $12 \times 12 \mathrm{cms}$. No regional lymph node enlargement was noted at that time. Whole of the ulcer with a $2 \mathrm{~cm}$. margin of healthy skin was excised. The defect in skin was closed by partial thickness skin graft. Histopathological examination of the excised tissue was suggestive of poorly differentiated squamous cell carcinoma.

8 months after surgery \& skin grafting, the patient came with exophytic ulcerated growth of size $7 \times 7 \mathrm{~cm}$. near angle of right scapula. It was fixed to underlying muscles of back. 
Patient was also having another fungating growth in left axilla which was $6 \times 6 \mathrm{cms}$. in size, fixed to underlying structures causing restriction of movements at shoulder. Serous discharge was present from axillary growth. There was no vascular or neurological impairment present in left upper limb. Biopsy from axillary growth was positive for squamous cell carcinoma.

LITERATURE REVIEW: The eponym "Marjolin's ulcer" was derived from French surgeon Jean Nicholas Marjolin in 1828 who observed and classified cellular change in burn skin and coined the term "ulcere cancroide".(4) The skin lesion underlying development is predominantly burn scar $(75 \%)$, traumatic non healing wound $(8 \%)$, venous stasis ulcer $(6 \%)$, pressure ulcer $(3 \%)$ and other e.g. Frost bite, vaccination scar .(1)

The latency period is inversely proportional to patient's age at the time of skin injury. In chronic Marjolin's ulcer it ranges from 20-40 year as transformation from non-healing wound to malignant disease is slow. The average time lag between the burns and subsequent malignant ulceration is 19 years. (5) In acute Marjolin's ulcer it occurs within few weeks to one year.(1) Average age at diagnosis of Marjolin's ulcer is in $5^{\text {th }}$ decade of life with a range of 18-84 years. (2) It is seen more frequently in males as compare to females with ratio of 3:1.(2) Most commonly it is located on lower extremities (53\%), upper extremities (18\%), trunk (12\%), face and nape (5\%), scalp (9\%). ${ }^{(4)}$

Aetiology of Marjolin's ulcer is not yet clear. Many hypotheses have been suggested. Slow healing and scar instability characterized by chronic irritation and the induction of constantly proliferating epidermal unit have been blamed. Repeated cycle of healing and breakdown, wound that never healed and application of irritant medication are all result in reduced ability to withstand carcinogens. ${ }^{(6)}$ As a result of constant breakdown of ulcer, a nutritional deficiency develops, owing to release of toxins by autolysis and heterolysis of scar. This yields an epithelium that is unable to withstand the carcinogens produced by skin because of excessive heat and radiation. (7) Ultraviolet rays are also found to be associated with Marjolin's ulcer. On histological examination of sun damaged skin, dyskeratosis and vacuolated keratinocytes known as sun burn cell are seen. Marjolin's ulcer least frequently founds on trunk which is not frequently exposed to sunlight. (8) It has also been suggested that relatively avascular scar tissue act as immune privileged site that allows the tumour to resist body defences against foreign cell.(6)

Scar tissue acts as a barrier for the tumours, if we release this barrier, the virulent spread of the tumour will be permitted. (8) Regional lymph node metastasis and recurrence after surgery is not uncommon. Metastasis to regional lymph nodes is seen in $30 \%$ of cases and local recurrence occurs in $17 \%$ of patients. The median interval to recurrence after surgery is 15 months. Locoregional recurrence is more common in female patients and those with high-grade tumours. (9) Poorly differentiated squamous cell carcinomas have a tendency to spread to lymph nodes earlier. Squamous cell carcinomas resulting from the Marjolin's ulcer have a much greater tendency to metastasize than squamous cell carcinomas resulting from the other causes (10).

Various studies suggested that all chronic wound should be closed surgically either by skin graft or skin muscle flap. Large wound should not be left for secondary intention healing. Burn scar from childhood should be carefully monitored; biopsy of any suspected lesion should not be delayed. At present no standard treatment for Marjolin's ulcer is suggested. Surgery remains the first treatment of choice. Marjolin's ulcer should be excised with a $2 \mathrm{~cm}$. margin of normal healthy tissue, which may necessitate amputation with lesion involving joint space or deep local extensive invasion. Although classically $2 \mathrm{~cm}$ safety margin is still widely used for resection of primary squamous cell carcinoma Marjolin ulcers, $2.5 \mathrm{~cm}$ safety margin is better for

Journal of Evolution of Medical and Dental Sciences/Volume1/Issue5/November-2012Page-690 
resection in recurrent cases.(11) Axillary \& inguinal lymph node dissection should be done if nodes are found to be positive. Radiotherapy and chemotherapy can be instituted on individual basis. $(1,2)$ Chemotherapeutic agents most commonly used are 5-fluorouracil, methotrexate, bleomycin, cisplatin.(8) Indication of radiotherapy include - tumour $>10 \mathrm{cms}$. in size with positive regional lymph node ( to be given after regional lymph node dissection), head \& neck lesion with positive regional lymph node, patient with inoperable regional lymph node metastasis. ${ }^{(8)}$

Lifeso and Bull describe histological classification with include grade I (well differentiated), grade II (moderately differentiated), grade III (Poorly differentiated) tumours.(12) Tumours which have latent period of $>5$ years, situated over trunk and lower limb, infiltrative form, poorly differentiated and presence of regional lymph node metastasis have worse prognosis. ${ }^{(4)}$ Stage and grade of the tumor, presence of metastases and presence of local recurrence are the main predictors of death.(13)

CONCLUSION: Marjolin's ulcer should be considered as a significant post-burn complication; (5) it should be treated with full emphasis on adequate local clearance and regular follow up for many years; if not treated adequately, it may lead to complicated recurrence.

\section{REFERENCES:}

1. Wojciech MW, Andrzej LK, et al. Two Different Cases of Marjolin's Ulcer and Recommendations for Practice. The Open Surgical Oncology Journal, 2010; 2: 8385.

2. Interesting Case Series, Chronic Ulcer. Correspondence: williamaboumd@hotmail.com William Abouhassan, MD, Johns Hopkins Burn Center, Johns Hopkins University, Baltimore, Md. http://www.eplasty.com/images/PDF/eplasty-d-10-00007.pdf Date of access $01 / 10 / 2012$.

3. Copcu, Eray. Marjolin's Ulcer: A Preventable Complication of Burns? Plastic \& Reconstructive Surgery, July2009; 124(1): 156e-164e.

4. Tomasz Wojewoda, Wojciech M. Wysocki, Jerzy Mituś. Marjolin's ulcer - case report and literature review. Polish Journal of Surgery 2009; 81(9): 414-418.

5. E. Copcu, A. Aktas, N. Şişman, Y. Oztan. Thirty-one cases of Marjolin's ulcer Clinical and Experimental Dermatology March 2003; 28 (2):138-141.

6. Ifeanyi IO, Bismark Okwor, Wilson IBO. Penetrating scalp Marjolin's ulcer involving bone and dura mater in a Nigerian hospital: Case report and literature review. Burns (2009), doi:10.1016/j.burns.2009.04.010.

7. Malheiro E., Pinto A., et al. Marjolin's Ulcer of the scalp: case report and literature review. Annals of Burns and Fire Disasters - vol. XIV - n. 1 - March 2001.

8. Eser Aydoğdu Serkan Yildirim, Tayfun Aköz. Is surgery an effective and adequate treatment in advanced Marjolin's ulcer? Burns June 2005; 31(4): 42143.

9. Dr A. Eroğlu, S. Çamlibel. Risk factors for locoregional recurrence of scar carcinoma British Journal of Surgery 1997; 84(12): 1744-6.

10. Ozek Cuneyt, Celik Naci, et al. Marjolin's Ulcer of the Scalp: Report of 5 Cases and Review of the Literature. Journal of Burn Care \& Rehabilitation Jan./Feb. 2001; 22(1): 65-69. 
11. Abdolazim Ghalambor. Marjolin ulcer: How much of safety margin needs resection along marjolin ulcer squamous cell carcinoma in recurrence cases Pak J Med Sci May-June 2007; 23(3): 394-397.

12. Lifeso RM, Bull CA. Squamous cell carcinoma of the extremities. Cancer. 1985; 55:28622867.

13. Phillipo L Chalya, Joseph B Mabula1 et al. Marjolin's ulcers at a university teaching hospital in Northwestern Tanzania: a retrospective review of 56 cases. World Journal of Surgical Oncology 2012; 10:38.

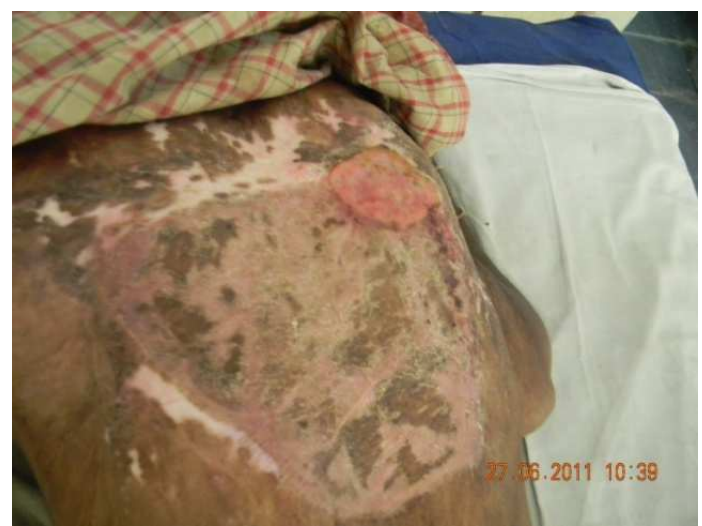

Figure 1: Marjolin's Ulcer arising in a Burn Scar

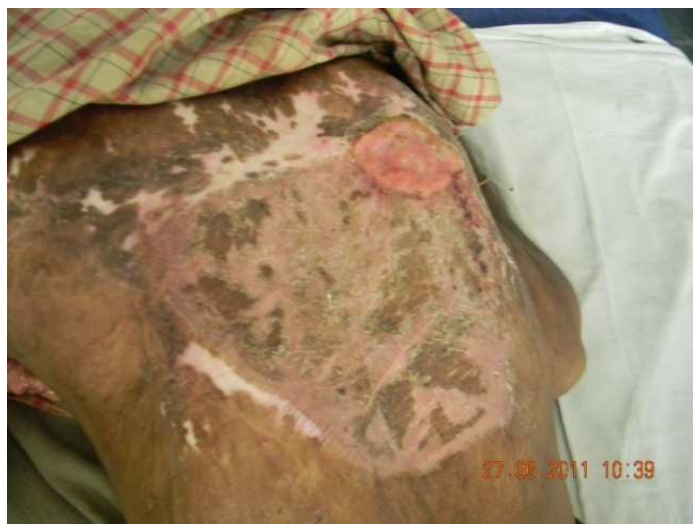

Figure 3 : Marjolin's Ulcer on back

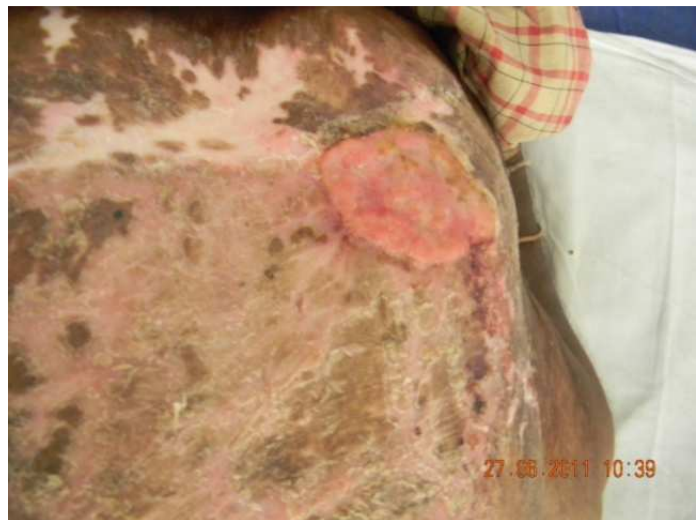

Figure 2: Exophytic Marjolin's Ulcer

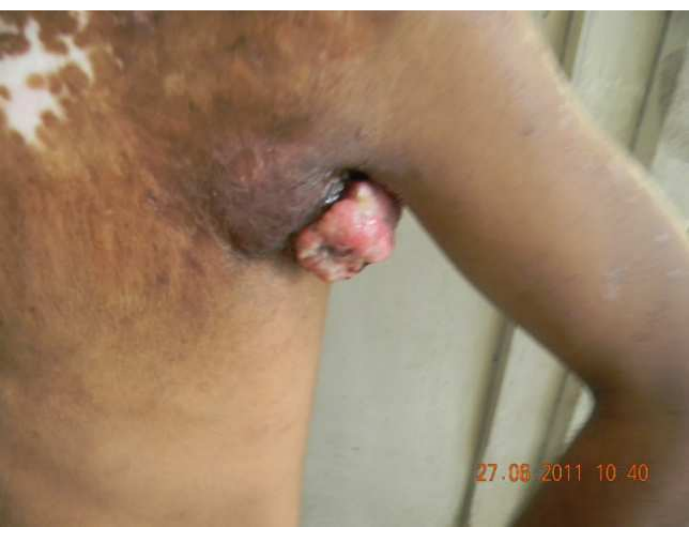

Figure 4: Regional Lymph Node Metastasis in case of Recurrent Marjolin's Ulcer on back 